\section{UNIVERSITY OF WISCONSIN}

Principles of Adult Education. Philosophy, principles, and practices of adult education as recognized in programs of various adult education organizations. Fall.

Extension Course in Agriculture and Home Economics. Relationships and legal status of the various services for agriculture and home economics. Fall.

Leadersbip in Agricultural Education. An analysis of the leadership function with consideration of the specific responsibilities of rural leaders; techniques of leadership and methods of developing local leaders. Fall.

Field Practice in Extension. Fall and Winter.
Independent Reading in Adult Education. Reading in the special field under the guidance of the staff. Fall and Spring.

Improvement of Adult Education Courses. Critical survey of problems in adult education; their social and educational bases; completed and needed research; examination and analysis of proposed solutions related to program improvement. Winter.

\section{UNIVERSITY OF WYOMING}

Adult Education. An introductory course planned particularly for public school personnel.

Problems and Tecbniques of Group Leadersbip.

Scbool and Community Relationsbips. A directed study of the local community.

\title{
some common interests of adult education leaders
}

\author{
Thurman White \\ Dean, Extension Division University of Oklaboma
}

Perhaps the most striking characteristic of the field of adult education is the independence of the activities within it. Although some activities are tied together by affiliation with some sponsoring agency, there are literally thousands of programs which seem totally unrelated to one another. In a chapter entitled "The Adult Educational Jumble", Adams has written:

When I first began to examine the literature on adult education expertly recommended to me, I had much the same feeling of suffocating helplessness which a parachutist may experience when he has dropped from the skies alone and landed in an impenetrable jungle. To mention only some of the flora, so to say, which first met my eye, there was an entire shelf full of nice little books, each dealing with some topic somehow related to adult education, but the topics seemed wholly unrelated to each other. Then I tried to get a bird's eye view so as to survey all these things as an integrated whole, and I read Miss Mary L. Ely's excellent $A$ dult Education in Action, a volume of well on to five hundred pages with a hundred and sixty-three chapters, sections, or what have you, by almost as many authors. We may mention, wholly at haphazard, a few of the headings: "Denver's Opportunity School", "A Thousand Little Theaters", "Hull House", "A Hobo School in a Western Railroad Yard", "The Deeper Significance of Radio", "A Self-Taught Boy", "Church Nights in a Suburban Church", "Training on the Job", and "The Importance of Service Stations". Again, we began to reach frantically for an "integrated whole". We wondered what the book really was about and were rather re- 
lieved when, towards the end of Charles Beard's Foreword, we read that it was "a mosaic out of discrete contributions".

It was indeed, but after reading a good many more volumes, it dawned on me that that was precisely what adult education was. It is as broad as human life itself, and life, most assuredly, is "a mosaic made out of discrete (if not always discreet) contributions. ${ }^{1}$

The great variety of educational programs is a result then of a great variety of "discrete contributions". They express the educational interest of a great number of diverse organizations, which in a sense represent and foster the American tradition of individual freedom. Any person or group may start an educational program and qualified persons are free to participate according to their interests. However, a system of independently operated educational programs has three important weaknesses.

The first weakness is the secondary position which the educational program frequently holds in an over-all organizational program. The effort to provide learning opportunities is often a marginal interest of an organization, and may even be used as a means for furthering some other organizational purpose. For example, some of the early workers' educational programs appeared to be designed more for the election of certain pro-labor public officials than for growth in total civic participation. In such cases individual learner needs are often relegated to a position of secondary importance and, if in conflict with the primary organizational objectives, may be completely overlooked.

The second weakness lies in the duplication of activities by several agencies. Some duplication results from the complete ignorance which leaders have of one another's programs. It is not at all unusual to find that a dozen organizations in a community with a common objective, such as "to improve home and family living", are unfamiliar with each other's activities. Competition for clients or financial support often results. As a protection against overlapping and duplicating programs, some communities have turned to a "community chest" financing technique.

Wasteful as competitive and duplicating programs may be, perhaps even more regrettable is the third weakness: The omission of important learning opportunities. Individual organizations, while operating strong programs, usually leave voids in filling certain needs which a well coordinated system of adult education could remedy.

An approach to the problem is the cooperative training of adult education leaders. Almost a decade ago, according to Van Sant, Cyril O. Houle called attention to the need for a common base in adult education leadership. $\mathrm{He}$ commented that:

Adult-educators have come into the professional field of adult education from such a variety of unrelated backgrounds that they have difficulty in understanding each other. This had led to a great duplication of effort and a needless search over the same problems rather than a cooperative approach based on an accepted common base from which to proceed. Perhaps this would not be such a handicap if it were possible to approach the areas of 
need at a leisurely pace. But events are rushing pell-mell into an era of vast expansion of adult education, and decisions have to be made and programs established in the pressing present.

Now, is cooperative training feasible? It is, you may say, if the various leaders want it. And therein lies the problem. What is "it"? What, in other words, do the various leaders want in the way of training? What are their interests? Unless the various leaders want the same thing, a program in which they will all cooperate is improbable. On the other hand, if it can be demonstrated that they have a common core of interests, the possibility of joint effort is considerably enhanced. This is the story of such a demonstration. What follows is a report of a study which isolated a few in-service training topics in which adult education leaders have a high degree of common interest. ${ }^{3}$

First, some definitions:

1. Training interests-refers to those aspects of the educational program in which adult education leaders would like to have additional learning in order to improve their performance in their programs.

2. Adult education program - a series of organized learning activities in which mature people purposefully participate on a part-time basis for the satisfaction of individual needs.

3. Adult education agency-any institution, association, club, or group that provides an adult education program.

4. Leaders-directors, supervisors, committee chairmen, coordinators, and other persons directly responsible for an adult education program.

\section{methodology of the study}

The purpose of the study required the development of special techniques. No other study had previously made a direct attack upon the professional improvement interests of adult education leaders. The first requirement was to make a decision as to topics on which the leaders would express their training interests. The procedure adopted for making this decision was as follows: (1) Review of the literature for knowledge required of leaders of adult education programs; (2) review of the literature for suggestions concerning a suitable methodology for use in the investigation; and (3) further reference to the writings of specialists and to a panel of adult education practitioners for suggestions on the specific content and form. By this procedure it was determined that in order for the topics to adequately cover the problems of program management, it would be necessary for the leaders to have an opportunity to express their interests in 14 general subject matter areas. These 14 areas are:

\section{Program purposes}

2. Community analysis

3. Psychology of adult learning

4. Staff

5. Recruitment and morale

6. Methods

7. Materials

8. Facilities

9. Equipment

10. Budget and finance

11. Public relations

12. Policy and control

13. Records and reports

14. Appraisal and evaluation 
The procedure also revealed the rank order method as suitable to the purposes of the study. The use of this method made it possible for the individuals and the leader sample to evaluate their interests in the various topics and rank them according to the degree of interest in each. The rank order method yielded data from which it was possible to make an inter-group comparison for each topic and also an inter-topic comparison. It was thus possible to isolate a core of topics in which the leaders had the greatest amount of common interest.

The content and form of the inventories used in the investigation were finally determined by reference to the writings of specialists and a panel of adult education practitoners. In order for the leader sample to express its interest in as natural a way as possible, it seemed desirable for the topics to be stated in the form of objectives and for the total inventory situation to resemble the selection of course objectives. The topics were stated in a form recommended by a recognized curriculum specialist. Each topic was mimeographed on a $3 \times 5$ card with a different color card used in each of three inventories. The number of topics included in an inventory was consistent both with the recommendation of a recognized psychometric authority and with the nature of the content being investigated. The 14 general categories made it advisable to use a multiple of 14 and the inventories each contained 28 topics.

The inventories contained specific topics which had been originally drawn from three sources: (1) The investigator's experience; (2) the rankings of adult education specialists; and (3) conferences with adult education practitioners. Out of his own experience and from an examination of various writings, the investigator prepared a list of more than 200 topics. These were approximately evenly distributed among the 14 general categories. A panel of nine adult education practitioners were then asked to vote upon the topics of most importance and to make additional suggestions. From the original list, additional suggestions, and conferences with the panel of practitioners, a final list of 112 topics was prepared. The topics were then randomly assigned from the 14 categories to four inventories. The decision to use three inventories instead of four and the refinement of administrative procedures were made during a series of eight trial administrations.

During the trial administrations, it was determined that adult education leaders would willingly perform the ranking task on the three inventories. Also, during the trial administrations, it was determined that the ranking behavior could be readily obtained by the use of the following instructions:

Here are twenty-eight topics for a class of adult education leaders. If you were in such a class, which of these topics would be most interesting to you? Please place the most interesting on top, the second most interesting next, and so forth on down to the least interesting on the bottom. There is no correct order; different topics are interesting to different people; just put the cards in the order that suits you. Use the back of this card to suggest any topics which would be important to you but are not 
included in this or one of the other sets of cards.

The trial administrations further served as an opportunity for perfecting an interview routine. A three-part routine was adopted as follows: (1) Establishing rapport by identification of the interview purpose, recalling any previous meeting with the interviewee, and discussing the program managed by the interviewee; (2) giving the predetermined instructions and observing the interviewee sort one of the inventories; and (3) discussing generally the interviewee's personal qualifications and background. One inventory was always ranked in the presence of the investigator; the other two were sometimes ranked in his presence and sometimes returned to him in a selfaddressed envelope furnished for that purpose.

After determining the content and form of the inventories to be used in the investigation and polishing the interview routine, attention was given to the reliability and validity of the inventories. Each of the inventories was re-ranked by 10 adult education practitioners after an interval of one month. The median coefficient of rank correlation obtained for the inventories was as follows: Inventory $\mathrm{A}, .813$; Inventory $\mathrm{B}, .812$; and Inventory $\mathrm{C}, .808$. After a consideration of the factors which might have influenced the second rankings, the reliability of the inventories was adjudged sufficient for the purposes of the investigation.

Both "face validity" and "presumptive evidence" were considered in the analysis of the validity of the inven- tories. The validity of the inventories was considered shown by: (1) the topics were judged to be suitable for a training program by adult education practitioners; (2) the leaders in the sample claimed to be ranking their interests in the topics; and (3) items which should have discriminated between the groups were found to have done so.

Following the development of a technique for obtaining expressions of interest, a technique was developed for obtaining a sample of adult education leaders. In selecting the sample considerable importance was attached to two considerations: (1) it would be possible to explore the interests of a relatively small number of adult education leaders, and (2) the purpose of the investigation required the exploration of interests among leaders of several of the wide variety of adult education programs.

The fact that the sample had to be limited to a small number meant that the requirements of the small sample theory would have to be satisfied. Since a simple random sample was impossible, it was necessary to find a statistical test of randomness. The test selected was the analysis of the variance. By this test, it is possible to obtain an estimate of the likelihood that individuals in several different groups are homogeneous with respect to a certain characteristic, and, hence, that they are from the same population. The analysis of variance was also a suitable technique for estimating the similarity of interests in a certain topic on the part of leaders from several adult education programs.

In order to avoid the extreme va- 
riability present in very small samples, it was determined that a minimum of 25 leaders was to be included in the sub-groups. It was then determined that the purpose of the study would be served by an exploration of the interests among leaders of four adult education programs.

With a view toward increasing confidence in the results of the study, it was decided to select four markedly different programs and to let chance play a principal role in the selection of the individuals included in each of the programs. Four of the programs most accessible to the investigator were: (1) American Association of University Women, (2) Public Schools, (3) Proprietary Schools, and (4) Personnel Training. An analysis was made of these programs with respect to the following six characteristics: (1) program content, (2) membership, (3) finance, (4) staff, (5) professional affiliations, and (6) leadership training. The analysis showed the programs to be markedly different.

The individuals within each were then selected for interviews upon a basis approaching randomness. Interviews were tentatively accepted with the first 40 volunteers from each program, and the first 25 inventories returned were accepted unless there was some reason for believing that the ranking performance was not according to instruction.

By these techniques data were collected from 100 adult education leaders with respect to their interests in in-service leadership training topics.

\section{findings}

The study showed that adult education leaders have a high common interest in the following topics:

1. To gain a better understanding of the basic needs which cause adults to participate in educational programs.

2. To gain a clearer insight into the changing interests of adults in vocations, religion, family, leisure time activities, health, and other areas of life.

3. To increase my ability to apply psychological principles to the selection of objectives.

4. To acquire techniques for relating our program more closely to the needs and interests of adults.

5. To acquire techniques for relating our program more closely to the general needs of the community.

6. To become more skillful in recognizing the community needs and resources that are important to adult education programs.

7. To develop a better understanding of the kinds of educational methods most suitable for mature people.

8. To develop a better understanding of the kinds of educational materials most suitable for mature people.

9. To become more familiar with procedures for "keeping up" with new developments and materials for adult education programs.

The presence of a common core of training interests among adult education leaders is of chief significance to the person who is concerned with the development of a leadership training program. The finding makes it 
clear that no agency has a monopoly on interests in many topics. The implication is that topical interests form a better basis for grouping than agency affiliation. A more homogeneous learning situation may be created by grouping the leaders according to their topical interests than by their agency affiliation.

The finding of a common interest core may also be of considerable importance to agencies which have the social responsibility for general leadership training. Such training agencies as universities may wish to give serious consideration to the fact that adult education leaders frequently want to learn about the same things and that association with a particular kind of program does not always lead to unique interests in self-improvement. The finding, in a sense, is a long step toward the removal of one of the barriers to offering general training programs for the adult education leadership.

The finding of a common interest core also offers an encouragement and inducement to the planning of community leadership training programs. The urban centers of America are liberally sprinkled with educational programs in which mature people participate. A visitor to almost any town will be told that "our town is very much over-organized". Almost without exception, each organization is jealous of its membership and its prestige. Each is proud of its success and satisfied that it is doing something unique. It will come as a surprise to many of the leaders of these varied organizations that they have common interests in certain fun- damental subject matters. The findings of this study clearly imply that a cooperative training program organized around topical interests might be successfully undertaken at the community level. Considerable educational benefit can accrue to a community from a successfully conducted cooperative training program. By association with one another in a training program, leaders will tend to eliminate needless repetition of error, overlapping, and duplication of programs, and in some cases, needless duplication of research.

The finding of a relatively small number of common interests at a high level may serve as a caution against the initial organization of a too-ambitious in-service training program. The implication is that the initial plans for a cooperative in-service training program should make provision for the consideration of a relatively few topics. It is expected that other interests will be developed during the course and that these developed interests may serve as a basis for subsequent training programs. It should be noted in this connection that observers of other adult education programs have reported maximum participation in programs organized around six to 10 meetings. The core topics found in the study are ample for a program of these dimensions.

Of some importance to the science of education is the implication that the findings strengthen the concept of a field of adult education. The fact of common interests means that, if the barriers of special vocabularies and particular terms are surmounted, 
there is a common identity in the entire field. General recognition of adult education as a field in the science of education seems to be slowly forming. Locating and publishing similarities of interests is perhaps insufficient to bring about any wide- spread realization by adult education leaders that basically they are engaged in the same process. However, the evidence of interest commonality must be added to the other factors indicating the reality of a field of adult education.

${ }^{2} J a m e s$ Truslow Adams. Frontiers of American Culture. New York: Charles Scribners Sons, 1944, p. 128.

${ }^{2}$ Thomas A. Van Sant, "Time for Courage". Adult Education Bulletin, XI (Feb. 1947), 78.

${ }^{3}$ Thurman White. Similarity of Training Interests among Adult Education Leaders,

Pb.D. dissertation, University of Chicago, 1950.

\title{
a review of professional preparation programs*
}

\author{
Elwin V. Svenson \\ Coordinator of Community and Program \\ Services, The Fund for Adult Education
}

The rapid expansion of adult education activities during the 1920's and 1930's introduced many people into a new kind of professional leadership position. These new adult educators desired professional training both for themselves and their staffs. Initially, requests for professional training were met by the establishment of in-service type programs, workshops, conferences, and seminars, usually held during the summer months. Such study opportunities were developed by many adult education operating agencies-often in cooperation with university extension divisions and university departments of education.

These early in-service training programs provided a stimulus to the de- velopment in schools of education of professional curricula leading to advanced degrees. In addition, university extension divisions improved and expanded opportunities for in-service training for the professional adult educator. Thus, universities through their schools of education and extension divisions came to provide leadership in training adult educators and developing content materials which are used by operating adult education agencies as well as by the universities.

The purpose of this study was, first, to identify institutions of higher learning whose departments or schools of education provide opportunities for professional study in adult education and, second, to analyze those

\footnotetext{
*This article is adapted from the introductory and concluding portions of Mr. Svenson's doctoral thesis, "A Study of Professional Preparation Programs for Leaders in Adult Education Offered by Schools of Education". University of California, Los Angeles. June, 1954.
} 